\title{
The Influence of the Illustrations on the Understanding of the Hebrew Written Text in the Elementary School in the Arab Sector in Israel
}

\author{
Janan Faraj Falah \\ Arab College for Education, Haifa, Israel \\ Email: jananf81@gmail.com
}

How to cite this paper: Faraj Falah, J. (2018). The Influence of the Illustrations on the Understanding of the Hebrew Written Text in the Elementary School in the Arab Sector in Israel. Creative Education, 9, 67-76. https://doi.org/10.4236/ce.2018.91006

Received: November 19, 2017

Accepted: January 28, 2018

Published: January 31, 2018

Copyright $\odot 2018$ by author and Scientific Research Publishing Inc. This work is licensed under the Creative Commons Attribution International License (CC BY 4.0).

http://creativecommons.org/licenses/by/4.0/

\begin{abstract}
This article examines the impact of illustrations and images in the Hebrew textbooks on the students' understanding of the texts, and the extent of using details out of these illustrations in the process of understanding of the written text, furthermore, their impact on developing imagination and discussions on the basis of these drawings within class. The Arab students begin to learn Hebrew in the third grade, after spending the last two first years in studying their native language, a process which involves great efforts, for the gap between the Arab spoken language and the literary one is great. By the time the students begin to learn Hebrew as a second language, most teachers use a variety of illustrative tools in order to demonstrate tasks and material. The use of images to describe words is the first stage, then using of illustration to present the text's subject, becomes the next phase. In this phase, the illustrations mediate between the student and the textbook, replacing the role of words and enable the students, who are not capable of using the Hebrew language quite good yet, to learn the new words. This study examines the relation between illustrations and textbooks through Hebrew class observations and interviewing of the students in the third and fourth grades in the "Terra Santa School" at Acre.
\end{abstract}

\section{Keywords}

Illustrations, Hebrew as a Second Language, Teaching Strategies, Visual Illustration, a Dialogue, Imagination, Arab Sector in Israel, Elementary School

\section{Introduction}

Illustrations in textbooks in general, and in children's literature in particular, are 
a mirror for visualization, for they illustrate a certain concept that is highlighted by the animator (Gonen, 1997). Children's pedagogical, social or national oriented stories might contain dual messages in their images and symbols, hidden or open, in order to convey the massage (Faraj Falah, 2013).

The illustrations make the book more creative and artistic (Nodelman, 1988), a language of visual communication, one of the main communication forms in modern culture (Shavid, 1996). Illustrations in children's books have some roles, a demonstrative one-to illustrate details and situations of the written text, and the other one is informative-to explain accurately elements which a child cannot imagine.

Historically, the illustrated, printed book is a direct development of handwritten manuscripts and The Media in the past, and writing was evolved through drawing and translated into visual images on decorated manuscripts on walls in hieroglyphs, in which the writing is determined by the direction people and animals look at. In later periods, religious subtitles were also written on the walls of churches (Gonen, 1997). Illustrations in children's books are relatively new historical phenomenon that had emerged on the $17^{\text {th }}$ century, aimed to alleviate children's learning difficulties during the long boring days at school. The reform accelerated at the end of the $18^{\text {th }}$ century and at the beginning of the $19^{\text {th }}$ century, mostly in Anglo-Saxon countries, in the course of the social spin that has taken over Europe mostly, with wider aesthetic and didactic aspects (Gonen, 2013).

As stated, England's citizens in the $18^{\text {th }}$ century, had become more aware to the importance of education for "climbing the social ladder" in the future, thus, they begun adding unique images and illustrations, specifically oriented for children (special decorations with strong bright colors on the book cover) in order to draw the children's attention to the book, and to lure them to open the book and read the story (Gordon, 2005).

At the same time, the illustration and images in the printed books had replaced the massages with more flexible elements, nevertheless, had created modern stimuli with stronger and meaningful experience, and the stories became happier and means for playing. In addition, at the end of the $19^{\text {th }}$ century, the illustrations and images have become strictly aesthetic in terms of color, of paper's quality and graphic design, all in an effort to provide the perfect artistic experience for the child (Gonen, 2013).

At the late of the $19^{\text {th }}$ century, children's literature is rich and substantial, full of illustrative stylish techniques, the illustration had turned the text into something much more artistic and visual (Northrab, 2012). At the beginning of the $20^{\text {th }}$ century, the illustrations were affected by the Plastic Arts of the western world, which has begun in the period of the Renaissance and continues to this day.

A book of illustrations was first published at the present time; this is a whole unique, artistic style, in which, the relation between images and words insert the messages (Winter, 2014). 
In Israel, images had started to show in children's literature since the 1940s, the first animator was Nahum Gutman, using vivid and clear images to provide children aesthetic experience, thus, the images simplify the telling of the story, yet, do not take over the place of the words and text. His first book was written by his father, S. Ben-Zion and was called "stories for Teenagers" (Mashiach, 2010).

At the beginning, the images and figures were about national deductive themes, however, these messages had changed according to the period, and by the beginning of the 1970s, it practically seized to exist. The themes described the child, the family, typically open and democratic family and society. Today the attitude is changed; the focus is primarily on individualism, with an emphasis on the child's social empowerment and multicultural encounters, for better acceptance of the Other (Peretz, 2016).

It is important to note that children's book illustrations address two audiences, the child and the matured illustrator, who draw the pictures that tell the story. Since the illustrator is exempted from the writing task, one is free to add interpretation, associations and personal experience to the drawings, and thus, consciously or unconsciously communicates with child. The reading requires the child to activate high levels of understanding and attaching together various pieces of information from several resources in order to obtain self-insights, thus, a task that is naturally not available for all readers, certainly not for all types of content. Illustrations and images allow children to understand situations which are simultaneously relate to the text, yet, function as an autonomous visual narrative for understanding and interpreting on different levels of realization (Mashiach, 2010).

Images and illustrations play a great role in understanding a text at time of childhood; children use illustrations to understand the plot and to receive information before the reading stage, and are affected by those image's style and content consciously, translating the visual phase into an emotion alone, in accordance with their values and beliefs (Yuval, 2009).

The illustrations in children's books can be used as means of decorating, interpreting and mood creating, and the child is able to interpret the images by the color, facial expressions from joy to sadness etc. The dynamics between the text and the picture is inseparable, as a single unit of different styles and colors, as a result, it creates rich piece in which both words and images are equally important (Gonen, 2004).

Numerous studies prove that images and illustration in books prevent the child from concentrating on the text and delay the development of the child's imagination, for the child's main focus is on the images rather than the text (Kita \& Eshel, 2006). This study, however, aims to examine the role of images in the development of imagination and illustration on students, and to shed light on this untested field, particularly among the Arab sector.

\section{Research Method}

1) The study subjects: 
The study was conducted in the third and fourth grades in "Acre Terra Santa School", with number of observations in the Hebrew lessons (Faraj Falah, 2017). Approximately 10 students were selected from each grade/class, 10 girls and 10 boys.

2) The Research tools:

a) Selected reading copies from Hebrew textbooks-without illustrations.

b) Original colored copies with illustrations from the same textbook.

c) Copies of illustrations without text.

d) Group interview with built up in depth questions.

3) The course of study:

a) A selection of text for 2 groups.

b) A division of groups into 4 -each of the 2 groups get a text adjusted to their age, 2 groups receive a text without illustrations, and the two other groups a text with illustrations.

c) Selection of illustrations from the textbooks, the groups are required to develop a text by the illustration that had been given to each group.

d) Each group is guided by students of the Academic Arabic College of the Hebrew language and literature in Haifa.

4) The study's goal:

The study aims to examine the role of illustrations in relation to understanding of the texts, do images and illustrations develop imagination and dialogues on the Hebrew lesson in Arabic elementary schools?

\section{The Findings}

The teacher and the children go to the Galil.

All the Children wear hats.

Sahar has a hat.

Salam has a hat.

Ayahas a hat.

Amir has a hat.

Adam has a hat. Only the teacher does not wear a hat. Why? For the teacher's hat was blowing in the Wind!

The two groups on the $3^{\text {rd }}$ grade were given first a simple text. The first group got only the text, without the illustrations, and had to answer the questions. The second group was given the questions basing on the text and the colored illustration (Figure 1), as it appears in the textbook.

In the first group, most students started to read the text, 2 students asked what a "Hat" means, the rest continued reading. At the final phase, the students were asked to tell the story as they understood it. They knew the children's names and the fact that they wore hats and the teacher did not, yet, they did not know the reason for the absence of the teacher's hat. Three of the students answered that the teacher's hat was absent for it fell in the course of running, 2 students answered that it is related to the wind. The last question was about their view about 


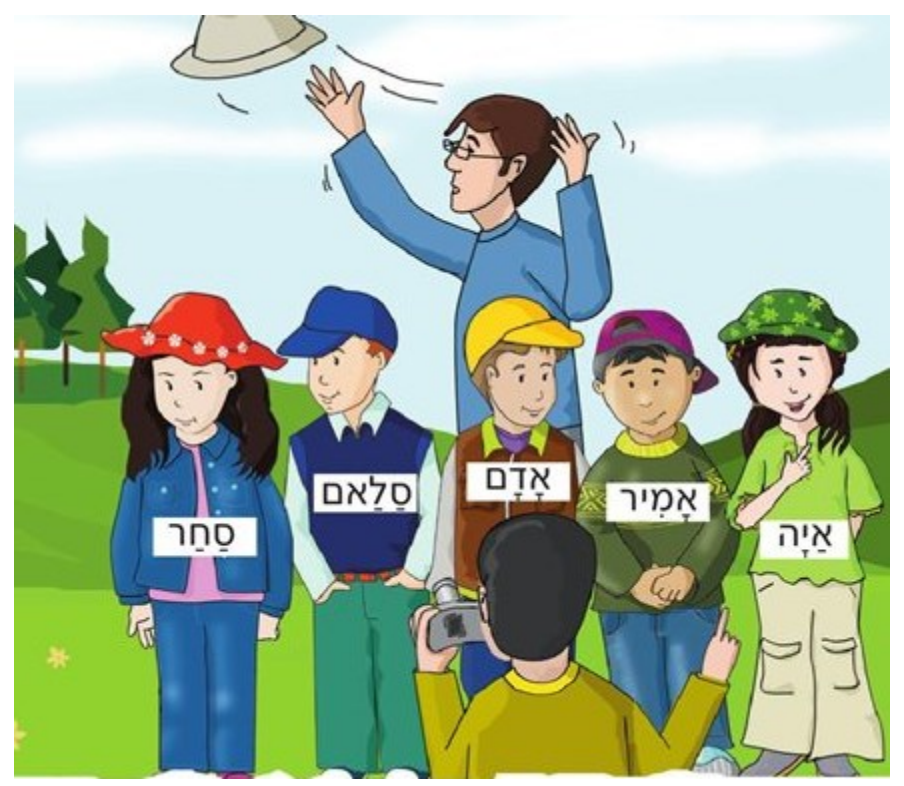

Figure 1. The teacher and the children go to the Galilee (Hebrew for the road).

the trip, or what did the students do in the trip. The answers were close: they all assumed that the trip was enjoyable; one student assumed it was hot weather for the students wore constantly their hats.

The second group, in comparison, did not start to read the text immediately; they looked at the picture and laughed about how the teacher holds his hat. The word "WIND" immediately rose without reading the text. The students of this group were louder; they constantly talked and compared the story with their trip. When they were asked the same questions (as in group 1), 5 of the students knew the right answer why the teacher did not wear his hat, as for the last question-of how was the trip, they immediately looked at the picture and said it was joyful for the children in the picture are smiling. By the green color of the picture's surrounding, 1 student was sure it was spring time, another student noticed the long sleeve the students wear, and another student said that a green surrounding also characterizing winter, for nature is covered green in the winter. Another answer denied the winter, for the student did not notice rain in the picture, and also to the fact that in winter they do not have trips in school, only in spring time.

The discussion in group 2 emphasizes the development of interest and imagination of the students, although the picture do not provide accurate indication, the students managed to extract the important information of the trip, the noise around the table also indicates of the children's active participation during the discussion.

\section{What does happen in winter in Israel?}

The days are short and the nights are long.

The temperatures are law and it is cold outside.

The wind is strong and cold. 
There are gray \& black clouds.

A rain falls down, it is sometimes accompanied with lights \& thunders.

Winter flowers flourish.

Birds fly from cold countries to Israel, sometimes they only pass in the way to warmer countries.

People wear warm clothes, turn the hit on at home and do not go outside as much.

Figure 2 was given to the $4^{\text {th }}$ grade. The first group received only the text, without the illustrations and begun reading it with the guidance of the academic students, every 5 pupils asked for the meaning of words "LIGHTENING" \& "THUNDER". After being explained for the meaning, the pupils have been asked the questions. Most of the pupils answered the questions easily and individually. In the final question of assumption-why do the birds pass to warmer countries, most of them answered that they cannot live in the cold, therefore they seek to find warmer places, there were no arguments, and the pupils focused on answering this question only.

The second group worked with the text and illustration (Figure 2), and as the first group of the $3^{\text {rd }}$ grade, they did not begin with the reading. First, they were looking at the picture and laughed at the birds that try to escape the rain, they said something like "look at the poor birds trying to escape the rain and the cold; it is cold for them as it is for us". Thus, they answered the last question of hypothesis before start reading. As similar to the first group of the same grade, many pupils asked for the meaning of "THUNDER" \& "LIGHTNING", and answered the questions easily. In the last question of why do birds move to warmer countries, the pupils looked at the picture and begun describing the birds' escape from the rain and the cold. There was also a comparison between the girls in the picture with the umbrellas and warm winter clothes and the birds which, unlike the happy girls, suffer from the rain. Another pupil compared the expression on the girls' faces with the expression on the birds', noticing that the birds clearly seem tired and scared!

In the third test, 20 pupils got the same illustration (Figure 3), and being

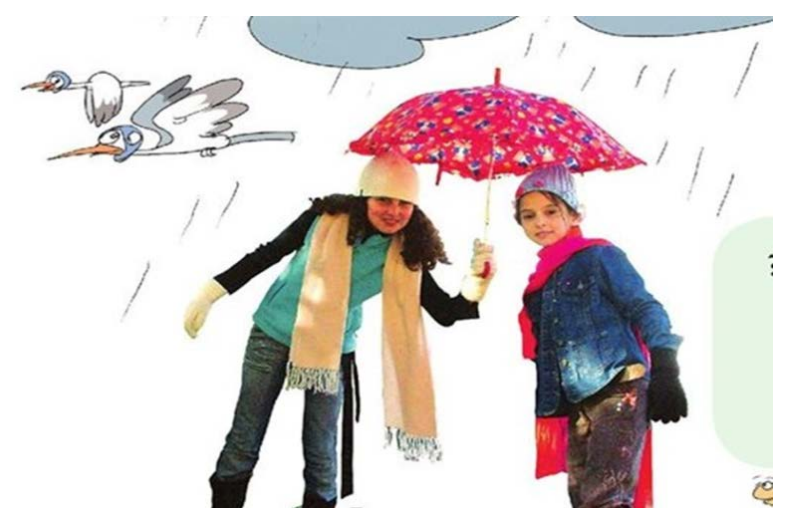

Figure 2. (It happens in the winter in Israel p. 60) (Hebrew to the road). 


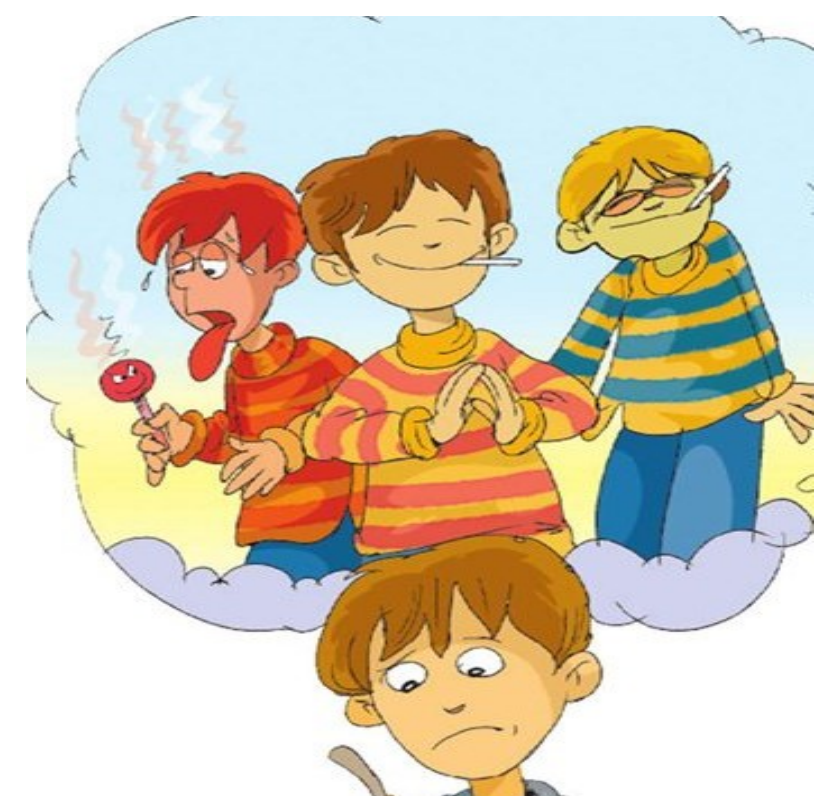

Figure 3. (A lollipop p. 8) Hebrew for the road.

asked to describe by writing a short story about the picture. After the test, I compared the pupils' stories with the original text in the book, in order to examine whether an illustration alone can develop guided imagery, communication and further discussions in the Hebrew lessons in Arab elementary schools.

Out of 20 students, 15 pupils identified the issue of Lollipop from the first minute, 5 pupils thought the children were smoking a cigarette, especially those children that only the candlestick sticking out of their mouth. 15 pupils raised different storylines about the lollipop, in accordance with the children's faces in the picture, assuming that not all the kids in the picture like the lollipop for some reason.

After the phase of ideas, the objects were asked to answer the last the question of hypothesis-why is the children's expression in the illustration not identical, and the reason for the fourth child in the Middle of the picture to hold the stick sadly? 10 pupils assumed that the children probably did not like the taste of the lollipop, almost all thought that the fourth boy in the picture is sad because his lollipop felt down, 5 objects assumed that the children in the picture like the lollipop, except for one who do not like its taste, or wanted lollipop with another taste.

After answering this last question, they were presented with the text:

A lollipop/By Shlomit Cohen Asif.

There is a lollipop which changes colors.

There is a lollipop which changes flavors.

The first taste is sweet to the tongue and lips.

And then becomes sour and less tasty.

Then it becomes hot and unpleasant.

And then salty. 
And finally.

It becomes bitter.

This also ends.

And nothing left.

Only the brown stick.

After reading the text, the objects became edgy, some were shouting that they knew the story, the rest, especially the pupils that assumed it is a cigarette, started to laugh, a discussion was developed in class between the pupils who ate this kind of lollipop, describing in Hebrew flavors of sour and sweet, and were shocked to discover that the fourth child in the picture was sad because its lollipop was finished.

\section{Discussion}

The current study examines the dynamics between words and illustrations. The role of illustrations in some parameters is mainly to develop imagination and dialogues in Hebrew classes among Arabs students.

For the Arab population, the Hebrew language is considered a second language. Arab students begin to learn Hebrew in the $3^{\text {rd }}$ grade; first they learn to recognize letters, then words and sentences, followed with demonstration of images. According to this research observation, all the worksheets included illustrations, whether in the subject of family, sweets or any other aspect.

According to the study, it was found that children, who received a text followed by pictures, were more active and open to ideas and assessments. As soon as they do not find the answer within the text, especially in the phase of the question of hypothesis, they immediately look at the picture. Furthermore, the discussions in these groups was richer and more interesting, also in cases of unpredictable and untypical answers of the students in this particular age. As opposed, the group who got the texts without the pictures, the answers were more focused with a wider agreement among the group's members, and they constantly were looking for answers in the text.

As for the third part and the general test, in which the student had been asked to answer the questions basing on the picture only, and to write a story or text out of the illustration, it was found that the students made greater use in their imagination, and tried to find the answers together, consulting and persuading each other in their theory.

The findings reveal that the combination of text and pictures led to the best results in the tests, moreover, it was found that students who worked on a text with illustrations are more creative and imaginative, deeper their thoughts and have greater memory of the text, than students who had other tests. Another profound element in the work was their joint efforts as a group, a situation which develops and increases the sense of belonging and mutual trust between the team members, and enhancement of the learning experience. The students encouraged each other; it made them feel confident, for they were able to express 
themselves to their guide and friends without hesitation or fear. This teaching method will contribute greatly if implemented fully in language studies, especially in teaching Hebrew as a second language; the mutual work would increase motivation and active attendance in class, and would prevent barriers among weak students.

\section{A Summary}

An illustrated textbook is a book of visual communication. According to this study, illustrations are dominant if they envision the text, illustrating it and promote understanding. Furthermore, illustrations and images increase considerably the process of thinking and imagination.

The illustrations in the series of textbooks of "Learning Hebrew" "Ivrit Laderech") were developed for the Arab sector on the basis of the series of "Key Signs" (Laderech, 2007) in collaboration of Hebrew teachers and consultants of the Ministry of Education. The new series, in contrast to the previous one-that had an undeveloped, simple and monotonous illustrations, has undergone a makeover: the illustrations became colored and contained new social and cultural subjects with built-in worksheets, that correspond the text and enable an appropriate learning strategy towards significant and creative learning, further thinking and further use of imagination in the phases of elementary school. This method of teaching emphasizes the importance of illustrations, open discussion within a study-group or with their teacher, and leads to empowerment and development of self-confidence and trusting of the self.

\section{References}

Faraj Falah, J. (2013). The Portrayal of Women in Israeli Arabic Textbooks on Druse Heritage. Us-China Educatin Review, 3, 33-37.

Faraj Falah, J. (2017). The Issue of Gender in Elementary Schools' Hebrew Textbooks for the Arab Sector in Israel Manuscript. British Journal of Education, Article ID: BJE-413.

Gonen, R. (1997). An Illustrated Children's Book Does Not Mean a Text with Pictures. Children's Literature, 24, 34-40.

Gonen, R. (2004). Four Dimensions to Illustration: The Cognitive, Value, Artistic \& Psychological Function of Illustrations in Contemporary Children's Book Illustrations. OlamKatan, 2, 111-140.

Gonen, R. (2013). Enjoy \& Cry: Children's Illustration as a Transformative Medium from Amnesia to Suffering. The Theory and History Unit, Bezalel//Issue Number 28-Illustration: A Dialogue between Text and Image. Tel Aviv-Jaffa: Am Oved.

Gordon, A. (2005). Figures in Hebrew: The Hebrew Illustrated Textbook for Children, The International Age 1900-1925 (pp. 19-24). Tel Aviv: The Nahum-Gutman Museum.

Kita, B., \& Eshel, M. (2006). Illustrated Textbooks: A Contribution to the Expand and Increase of Children's Vocabulary. Study \& Research in Training Teachers, 10.

Laderech, E. (2007). The Center for Educational Technology. Education Ministry. Jerusalem, 2-3-4. (Hebrew for the Road)

Mashiach, S. (2010). Allegory \& Illustration: Aesthetics and Politics in Children's Litera- 
ture. Children's and Youth Literature, 131, 33-62.

Nodelman, P. (1988). Words about Pictures: The Narrative Art of Children's Picture Books (p. 12). Athens, GA: University of Georgia Press.

Northrab, M. (2012). Picture Books for Children: Fiction, Folktales, and Poetry (p. 5). Chicago, IL: American Library Association.

Peretz, S. (2016). The Rainbow Children: Multiculturalism in Contemporary Children's Literature. A Study of Selected Pieces by Neomi Samuel \& Tamar Verta-Zehavi, with the collaboration of Abd-Al-SalamYunis. Educational Circles: Research, Studies, 6, 78-101.

Shavid, S. (1996). A Story Painting \& Writing (p. 20). Jerusalem: The Ministry of Education.

Winter, M. (2014). Changing Identities in Children's Literature. Levinsky College of Education. Levinsky College of Education Magazine of Culture, Society \& Education, $66,100-112$.

Yuval, N. (2009). The Dialogue between Text \& Illustration in Children's Literature. Studies in Children's Literature, 19, 66-76. 